ARTICLE

\title{
Synergistic electroreduction of carbon dioxide to carbon monoxide on bimetallic layered conjugated metal-organic frameworks
}

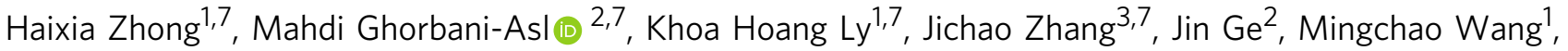
Zhongquan Liao ${ }^{4}$, Denys Makarov (1) ${ }^{2}$, Ehrenfried Zschech ${ }^{4}$, Eike Brunner ${ }^{1}$, Inez M. Weidinger ${ }^{1}$, Jian Zhang ${ }^{1,5}$, Arkady V. Krasheninnikov ${ }^{2,6}$, Stefan Kaskel (1) 1, Renhao Dong (i) ${ }^{1,8}$ \& Xinliang Feng (1) 1,8凶

Highly effective electrocatalysts promoting $\mathrm{CO}_{2}$ reduction reaction $\left(\mathrm{CO}_{2} \mathrm{RR}\right)$ is extremely desirable to produce value-added chemicals/fuels while addressing current environmental challenges. Herein, we develop a layer-stacked, bimetallic two-dimensional conjugated metalorganic framework (2D c-MOF) with copper-phthalocyanine as ligand $\left(\mathrm{CuN}_{4}\right)$ and zinc-bis (dihydroxy) complex $\left(\mathrm{ZnO}_{4}\right)$ as linkage $\left(\mathrm{PcCu}_{-} \mathrm{O}_{8}-\mathrm{Zn}\right)$. The $\mathrm{PcCu}-\mathrm{O}_{8}-\mathrm{Zn}$ exhibits high $\mathrm{CO}$ selectivity of $88 \%$, turnover frequency of $0.39 \mathrm{~s}^{-1}$ and long-term durability $(>10 \mathrm{~h})$, surpassing thus by far reported MOF-based electrocatalysts. The molar $\mathrm{H}_{2} / \mathrm{CO}$ ratio (1:7 to 4:1) can be tuned by varying metal centers and applied potential, making 2D c-MOFs highly relevant for syngas industry applications. The contrast experiments combined with operando spectroelectrochemistry and theoretical calculation unveil a synergistic catalytic mechanism; $\mathrm{ZnO}_{4}$ complexes act as $\mathrm{CO}_{2} \mathrm{RR}$ catalytic sites while $\mathrm{CuN}_{4}$ centers promote the protonation of adsorbed $\mathrm{CO}_{2}$ during $\mathrm{CO}_{2} \mathrm{RR}$. This work offers a strategy on developing bimetallic MOF electrocatalysts for synergistically catalyzing $\mathrm{CO}_{2} \mathrm{RR}$ toward syngas synthesis.

\footnotetext{
${ }^{1}$ Center for Advancing Electronics Dresden (Cfaed) and Faculty of Chemistry and Food Chemistry, Technische Universität Dresden, 01062 Dresden, Germany. ${ }^{2}$ Helmholtz-Zentrum Dresden-Rossendorf e.V., Institute of Ion Beam Physics and Materials Research, 01328 Dresden, Germany. ${ }^{3}$ Shanghai Synchrotron Radiation Facility, Zhangjiang Laboratory, Shanghai Advanced Research Institute, Chinese Academy of Sciences, 201204 Shanghai, China. ${ }^{4}$ Fraunhofer Institute for Ceramic Technologies and Systems (IKTS), Maria-Reiche-Strasse 2, 01109 Dresden, Germany. ${ }^{5}$ Department of Applied Chemistry, School of Applied and Natural Sciences, Northwestern Polytechnical University, 710129 Xi'an, China. ${ }^{6}$ Department of Applied Physics, Aalto University, P.O. Box 11100FI-00076 Aalto, Finland. ${ }^{7}$ These authors contributed equally: Haixia Zhong, Mahdi Ghorbani-Asl, Khoa Hoang Ly, Jichao Zhang. ${ }^{8}$ These authors jointly supervised this work: Renhao Dong, Xinliang Feng. ${ }^{凶}$ email: renhaodong@tu-dresden.de; xinliang.feng@tu-dresden.de
} 
E lectrocatalytic carbon dioxide reduction reaction $\left(\mathrm{CO}_{2} \mathrm{RR}\right)$, coupled to renewable energies, offers sustainable opportunities towards the production of value-added chemicals and carbon-based fuels ${ }^{1,2}$. Specifically, the electrochemical reduction of $\mathrm{CO}_{2}$ to $\mathrm{C}_{1}$ products (i.e., formic acid and $\mathrm{CO}$ ) is of high relevance for the chemical industry ${ }^{3-5}$, which can also yield a mixture of $\mathrm{CO}$ as carbon-reduced product and $\mathrm{H}_{2}$ as byproduct. This so-called syngas mixture with varying molar ratios of $\mathrm{H}_{2} / \mathrm{CO}$ is commonly used as precursor for hydroformylation process $\left(\mathrm{H}_{2}\right.$ : $\mathrm{CO}=1: 1)$, methanol synthesis of Fischer-Tropsch process $\left(\mathrm{H}_{2}\right.$ : $\mathrm{CO}=2: 1)$ and methanation process $\left(\mathrm{H}_{2}: \mathrm{CO}=3: 1\right)$ to produce high-value/energy-dense hydrocarbons/alcohols ${ }^{5,6}$. However, the $\mathrm{CO}_{2}$-to-CO conversion, involving the transfer of two electrons and two protons, typically suffers from high kinetic barriers and low selectivity due to the high thermodynamic/kinetic stability of $\mathrm{CO}_{2}$ and the competing hydrogen evolution reaction (HER) in aqueous media, respectively ${ }^{7,8}$. Recently, great efforts have been dedicated to explore numerous electrocatalysts for catalytic $\mathrm{CO}_{2} \mathrm{RR}$ to $\mathrm{CO}$, including noble metals ( $\left.\mathrm{Au}, \mathrm{Pd}, \mathrm{Ag}\right)$, transitionalmetal-based materials ( $\mathrm{Fe}, \mathrm{Co}, \mathrm{Ni}, \mathrm{Cu}, \mathrm{Zn}$ ) and heteroatom-doped porous carbons $2,7,9-17$. Nevertheless, these single site catalysts still fail to meet the requirement of electrochemical syngas synthesis with tunable $\mathrm{H}_{2} / \mathrm{CO}$ ratio (from 1:1 to $3: 1$ or higher) at relatively low overpotential. Therefore, the development of electrocatalysts with high activity and selectivity that enables tuning the competitive reactivity between the $\mathrm{CO}_{2} \mathrm{RR}$ and HER at room temperature is imperative.

Metal-organic frameworks (MOFs) are one class of highly ordered crystalline coordination polymers, which are emerging as highly attractive catalytic systems due to the uniquely combining homogenous and heterogeneous features: First, the incorporation of well-defined and highly active sites into a defined and stable scaffold ensures excellent catalytic activity and selectivity; second, the porous metrics allow for sufficient and controllable mass transfer to and from the embedded active sites; finally, the molecularly defined catalytic environment around the active site allows for tuning the catalytic reaction by modifying the scaffold and facilitates deriving fundamental understanding of catalytic mechanism. For example, Co-PMOF and $\mathrm{Al}_{2}(\mathrm{OH})_{2} \mathrm{TCPP}-\mathrm{Co}$ MOFs have been developed for electrocatalytic $\mathrm{CO}_{2} \mathrm{RR}$ to $\mathrm{CO}$ with high selectivity $(>70 \%)^{8,13,18}$. However, conventional MOFs suffer from certain drawbacks including their intrinsically low conductivity (electrical insulators) and the blockage of metal centers by organic ligands, which have greatly hampered their development for promoting $\mathrm{CO}_{2} \mathrm{RR}$. Recent researches have demonstrated that layered 2D conjugated MOFs (2D c-MOFs) ${ }^{19-23}$ with fully in-plane $\pi$-delocalization along $2 \mathrm{D}$ directions and weak out-plane $\pi-\pi$ stacking exhibit higher density of exposed metal centers and improved electron conductivity (up to $2500 \mathrm{~S} \mathrm{~cm}^{-1}$ ) 24 apart from the inherited features of traditional MOFs, suggesting a great potential in high-performance electrocatalysis. For instance, the reported THT-Ni (THT $=$ triphenylenehexathiol) ${ }^{25}$ and THT$\mathrm{Co}^{26} 2 \mathrm{D} c$-MOFs with $\mathrm{Ni}(\mathrm{Co}) \mathrm{S}_{4}$ active sites afford superior HER electrocatalytic activity; $\mathrm{Ni}_{3}$ (hexaiminotriphenylene) $)_{2} 2 \mathrm{D} c-\mathrm{MOF}$ with $\mathrm{NiN}_{4}$ active sites ${ }^{27}$ and phthalocyanine (Pc)-based 2D $c$-MOF with $\mathrm{CoO}_{4}$ active sites ${ }^{28}$ can efficiently catalyze oxygen reduction reaction with onset potential of $0.82 \mathrm{~V}$ and half-wave potential of $0.83 \mathrm{~V}$ vs. RHE (reversible hydrogen electrode) in alkaline media, respectively. Inspired by these successes, we anticipate that $2 \mathrm{D} c$ MOFs should also act as promising electrocatalysts in enhancing $\mathrm{CO}_{2} \mathrm{RR}$ even though the related reports are rather limited ${ }^{29}$. Furthermore, the competitive reactivity between the $\mathrm{CO}_{2} \mathrm{RR}$ and HER can be presumably tuned by tailoring the structures and compositions of 2D $c$-MOFs. Therefore, as a proof-of-concept based on the above structural/property advantages, we rationally designed layered 2D $c$-MOFs with bimetallic centers to improve electrocatalytic $\mathrm{CO}_{2} \mathrm{RR}$ activity toward syngas synthesis; hereby one metal center will show high selectivity for $\mathrm{CO}_{2}$-to-CO conversion while the other metal center will be utilized for $\mathrm{H}_{2}$ generation due to its low binding energy of $\mathrm{CO}$ and high proton generation rate.

Herein, a 2D c-MOF electrocatalyst with bimetallic centers is synthesized by solvothermal approach for electrocatalytic $\mathrm{CO}_{2} \mathrm{RR}$. This 2D c-MOF consists of phthalocyaninato copper as the ligand and zinc-bis(dihydroxy) complex $\left(\mathrm{ZnO}_{4}\right)$ as the linkage, named as $\left(\mathrm{PcCu}-\mathrm{O}_{8}-\mathrm{Zn}\right)$. The electrochemical measurements indicate that $\mathrm{PcCu}-\mathrm{O}_{8}-\mathrm{Zn}$ exhibits highly selective catalytic activity for $\mathrm{CO}_{2}-$ to-CO conversion (88\%) and high turnover frequency (TOF) of $0.39 \mathrm{~s}^{-1}$ at $-0.7 \mathrm{~V}$ vs. RHE and excellent stability. Syngas compositions with different molar $\mathrm{H}_{2} / \mathrm{CO}$ ratio (from $1: 7$ to $4: 1$ ) can be tuned via varying the metal centers ( $\mathrm{Cu}$ and $\mathrm{Zn}$ ) of ligand/ linkage as well as applied potentials. Operando X-ray absorption spectroscopy (XAS) and surface-enhanced infrared absorption (SEIRA) spectroelectrochemistry are utilized to probe the catalytic sites and the reaction process. The spectroscopic studies combined with contrast experiments and density functional theory (DFT) calculation reveal that $\mathrm{ZnO}_{4}$ complexes in the linkages of $\mathrm{PcCu}-\mathrm{O}_{8}-\mathrm{Zn}$ exhibit high catalytic activity for $\mathrm{CO}_{2}$-to-CO conversion, while $\mathrm{CuN}_{4}$ complexes in the Pc macrocycles act as the synergetic component to promote the protonation process and hydrogen generation along with the $\mathrm{CO}_{2} \mathrm{RR}$. Thus, the bimetallic active sites contribute to a synergistic effect on the $\mathrm{CO}_{2} \mathrm{RR}$. Our work highlights the bimetallic MOF electrocatalyst for highly selective $\mathrm{CO}_{2} \mathrm{RR}$.

\section{Results}

Material design and reaction energetics. Density functional theory calculations were firstly employed to optimize the electrocatalyst design by simulating the reaction energetics of $\mathrm{CO}_{2} \mathrm{RR}$ and the competing HER on Pc-based 2D c-MOFs (PcM-O ${ }_{8}-\mathrm{M} 1$, $\mathrm{M}=\mathrm{Cu}$ or $\mathrm{Zn}, \mathrm{M} 1=\mathrm{Cu}$ or $\mathrm{Zn}$ ) (Fig. 1 and Supplementary Figs. 1-4 and Tables 1-7). Typically, the electrochemical $\mathrm{CO}_{2}$-to- $\mathrm{CO}$ reduction steps include the first proton-coupled electron transfer to generate a carboxyl intermediate $\left({ }^{*} \mathrm{COOH}\right)$, and subsequently the second charge transfer (one electron and one proton) for the formation of $* \mathrm{CO}$ intermediate, as well as the desorption of $\mathrm{CO}$ for the final CO product (Eqs. 1-3 in Supplementary Methods) ${ }^{30,31}$. On the other hand, HER goes through a proton $\left({ }^{*} \mathrm{H}\right)$ intermediate. The results of calculations reveal that the formation of ${ }^{*} \mathrm{COOH}$ via protonation is the rate-limiting step for $\mathrm{PcM}_{-} \mathrm{O}_{8}-\mathrm{M} 1$ (Fig. 1a, $\mathrm{c}$ and Supplementary Figs. 3, 4). The calculated binding energy values of the intermediates $\left({ }^{*} \mathrm{COOH}\right)$ and ${ }^{*} \mathrm{H}$ on $\mathrm{PcM}-\mathrm{O}_{8}-\mathrm{M} 1$ manifest a stronger interaction of $* \mathrm{COOH}$ intermediate and a weaker interplay of $* \mathrm{H}$ with the linkages $\left(\mathrm{M} \mathrm{O}_{4}\right.$ complexes) as compared with those of the phthalocyanine macrocycles $\left(\mathrm{MN}_{4}\right.$ complexes, Supplementary Tables 2-5). It is thus proposed that $\mathrm{M1O}_{4}$ and $\mathrm{MN}_{4}$ complexes serve as the catalytic sites for $\mathrm{CO}_{2} \mathrm{RR}$ and HER, respectively. On the other hand, in the $\mathrm{CO}_{2} \mathrm{RR}$ process, the $\mathrm{ZnO}_{4}$ complexes of $\mathrm{PcCu}-\mathrm{O}_{8}-\mathrm{Zn}$ display the lowest Gibbs free energy for ${ }^{*} \mathrm{COOH}$ formation and the lowest overpotential compared to other $\mathrm{MlO}_{4}$ complexes in $\mathrm{PcM}-\mathrm{O}_{8}-\mathrm{M} 1$ (Fig. 1a, c and Supplementary Figs. 3, 4 and Supplementary Table 6), suggesting that the electrochemical $\mathrm{CO}_{2} \mathrm{RR}$ to $\mathrm{CO}$ is energetically preferred for $\mathrm{PcCu}-$ $\mathrm{O}_{8}-\mathrm{Zn}$. In addition, the overpotential for $\mathrm{CO}_{2} \mathrm{RR}$ at $\mathrm{MlO}_{4}$ (Supplementary Table 6) has been found to be influenced by different $\mathrm{MN}_{4}$ complexes in the Pc ligand. For example, the over-

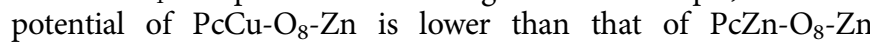
(while $\mathrm{PcCu}-\mathrm{O}_{8}-\mathrm{Cu}<\mathrm{PcZn}-\mathrm{O}_{8}-\mathrm{Cu}$ ), which reveals the important role of the Pc metal centers on promoting electrocatalytic $\mathrm{CO}_{2} \mathrm{RR}$. To achieve more insight into the role of Pc metal centers, we further compare the free energy profiles of $\mathrm{HER}$ on $\mathrm{MN}_{4}$ and 

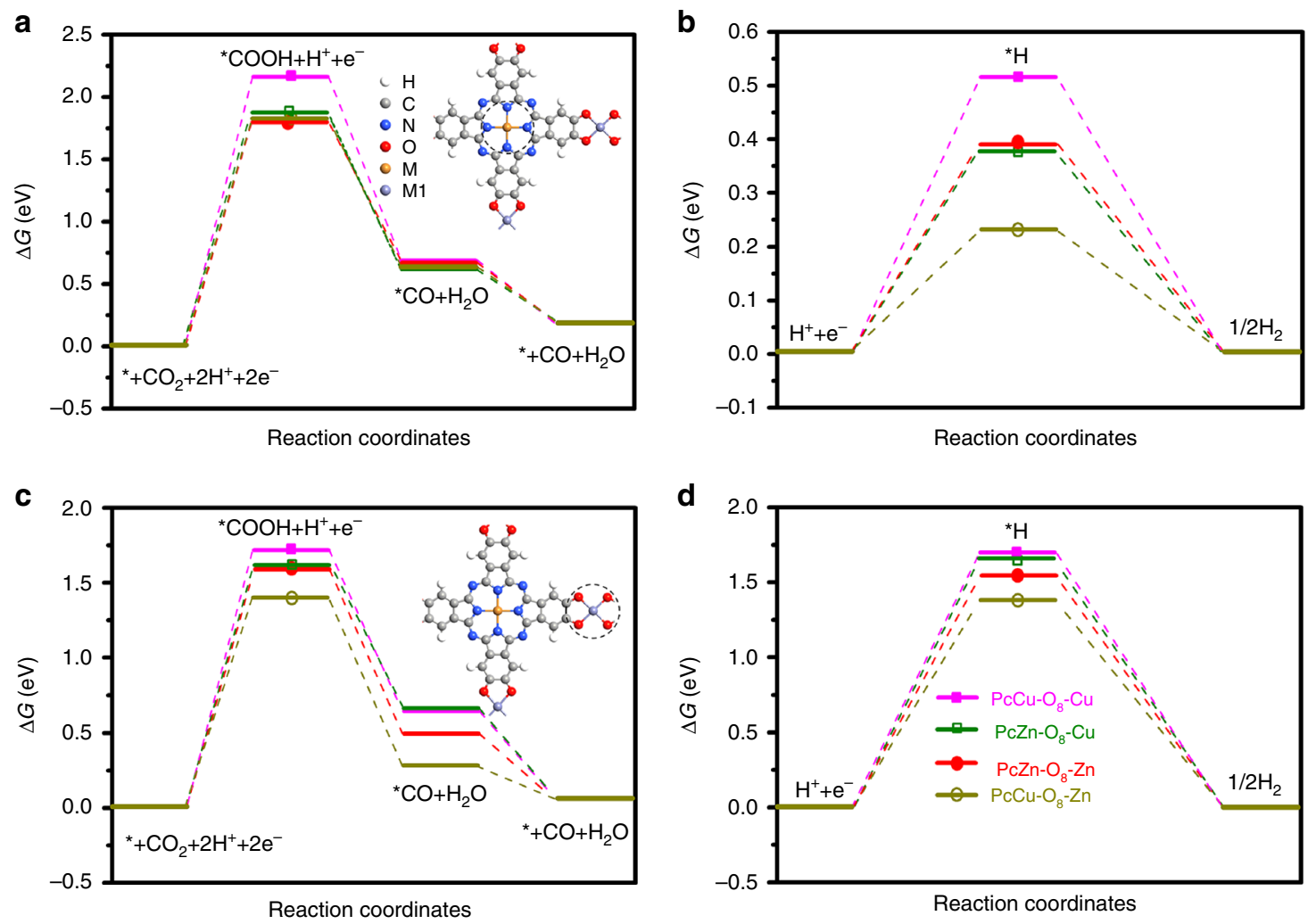

Fig. 1 DFT calculation of $\mathrm{CO}_{2}$ RR. $\mathbf{a}, \mathbf{b}$ Free energy profiles of $\mathrm{CO}_{2} \mathrm{RR}$ and $\mathrm{HER}$ on $\mathrm{MN}_{4}$ units of $\mathrm{PcM}-\mathrm{O}_{8}-\mathrm{M} 1$ at $U=0.0 \mathrm{~V}$, respectively. Inset in (a): atomistic structure of $\mathrm{PcM}-\mathrm{O}_{8}-\mathrm{M} 1$. The dashed circle indicates the catalytic active area with $\mathrm{MN}_{4}$ units. $\mathbf{c}$, $\mathbf{d}$ Free energy profiles of $\mathrm{CO}_{2} \mathrm{RR}$ and $\mathrm{HER}$ on $\mathrm{M}_{1} \mathrm{O}_{4}$ units in the $\mathrm{PcM}-\mathrm{O}_{8}-\mathrm{M} 1$ at $\mathrm{U}=0.0 \mathrm{~V}$, respectively. Inset in (c): atomistic structure of $\mathrm{PcM}-\mathrm{O}_{8}-\mathrm{M} 1$. The dashed circle indicates the catalytic active area with $\mathrm{M} 1 \mathrm{O}_{4}$ units.

$\mathrm{M} 1 \mathrm{O}_{4}$ complexes, which show that $\mathrm{CuN}_{4}$ complex in $\mathrm{PcCu}-\mathrm{O}_{8}-\mathrm{Zn}$ exhibits the lowest HER energy barrier and the fastest proton/ electron transfer kinetics among the different metal centers (Fig. 1b, d, Supplementary Table 7) ${ }^{32,33}$. Based on the above consideration, it is inferred that the presence of $\mathrm{CuN}_{4}$ complexes in the $\mathrm{PcCu}-\mathrm{O}_{8}-\mathrm{Zn} \mathrm{MOF}$ facilitates the protonation of adsorbed ${ }^{*} \mathrm{CO}_{2}$ on $\mathrm{ZnO}_{4}$ complexes, and thus accelerates the overall $\mathrm{CO}_{2} \mathrm{RR}$ kinetics. Therefore, a synergistic effect between $\mathrm{CuN}_{4}$ complexes and $\mathrm{ZnO}_{4}$ complexes is proposed for bimetallic MOF electrocatalysts.

Synthesis and characterization. Inspired by the above theoretical calculation, $\mathrm{PcCu}-\mathrm{O}_{8}-\mathrm{Zn} \mathrm{MOF}$ comprising of 2,3,9,10,16,17,23,24octahydroxy phthalocyaninato copper monomer linked by square planar $\mathrm{ZnO}_{4}$ linkages (Fig. 2a) was synthesized via solvothermal method (Supplementary Figs. 5-7), as confirmed by Fouriertransform IR (FT-IR) spectroscopy and powder X-ray diffraction (XRD) measurements. The disappearance of the ligand $\mathrm{OH}$ signals (3300 and $630 \mathrm{~cm}^{-1}$ ) and the peak shift from $1288 \mathrm{~cm}^{-1}(\mathrm{C}-\mathrm{OH})$ to $1270 \mathrm{~cm}^{-1}(\mathrm{C}-\mathrm{O}-\mathrm{Zn})$ in the FT-IR spectra (Supplementary Fig. 8) demonstrate the successful coordination of $\mathrm{O}$ to $\mathrm{Zn}$ atoms ${ }^{34}$. The XRD pattern (Fig. $2 \mathrm{~b}$ ) shows intense peaks at $5.0^{\circ}$, $7.1^{\circ}$ and $10.1^{\circ}$, assignable to (100), (110) and (200) plane, respectively, which indicates the long-range order within the $a b$ plane ${ }^{35}$. The broad peak at $27.3^{\circ}$ originates from the weak longrange stacking along the $c$ direction with a layer distance of 0.33 $\mathrm{nm}$, which is a typical feature of layered $\mathrm{MOFs}^{36}$. Compared to the calculated structures, the observed XRD pattern of $\mathrm{PcCu}-\mathrm{O}_{8}-\mathrm{Zn}$ is in a good agreement with the AA staggered stacking geometry. Scanning electron microscopy (SEM, Supplementary Fig. 9) images indicate aggregated nanosheets in the resulting MOF samples.
Transmission electron microscopy (TEM) images also present a mass of MOF nanosheets with an average size of $24 \mathrm{~nm}$ (Fig. 2c). The selected area electron diffraction pattern (SAED, inset image in Fig. 2c) and the high-resolution TEM (HR-TEM, Fig. 2d) images further manifest the crystalline structure of $\mathrm{PcCu}-\mathrm{O}_{8}-\mathrm{Zn}$ based on a square lattice of $1.75 \mathrm{~nm}$.

Element mapping images (Supplementary Fig. 10) disclose the homogenous distribution of $\mathrm{Cu}, \mathrm{Zn}, \mathrm{C}, \mathrm{N}$ and $\mathrm{O}$ in the $\mathrm{PcCu}-\mathrm{O}_{8^{-}}$ Zn sample. Furthermore, X-ray photoelectron spectroscopy (XPS) analysis also confirms the presence of $\mathrm{Cu}, \mathrm{Zn}, \mathrm{C}, \mathrm{N}$ and $\mathrm{O}$ elements (Supplementary Fig. 11). In the high-resolution $\mathrm{Cu} 2 p$ spectrum, the set of peaks at 936.7 and $953.8 \mathrm{eV}$ is assigned to $\mathrm{Cu}$ $2 p_{3 / 2}$ and $\mathrm{Cu} 2 p_{1 / 2}$, respectively, which suggests one type of oxidized $\mathrm{Cu}$ (II) in the $\mathrm{PcCu}-\mathrm{O}_{8}-\mathrm{Zn}^{37}$. The deconvolution of N1s spectra further verifies the coordination of $\mathrm{Cu}$ and $\mathrm{N}^{38}$. For the high-resolution scan of the $\mathrm{Zn} 2 p$ region, the typical feature of $\mathrm{Zn}$ (II) is found ${ }^{39}$.

To further investigate the chemical state of the $\mathrm{Cu}$ and $\mathrm{Zn}$ atoms in the $\mathrm{PcCu}_{-} \mathrm{O}_{8}-\mathrm{Zn}$ sample, XAS and extended X-ray absorption fine structure (EXAFS) analyses were performed. The $\mathrm{Cu}$ K-edge X-ray absorption near-edge structure (XANES) spectra (Supplementary Fig. 12) show that both $\mathrm{PcCu}_{-} \mathrm{O}_{8}-\mathrm{Zn}$ and the monomer $\mathrm{PcCu}-(\mathrm{OH})_{8}$ exhibit a typical $\mathrm{Cu}(\mathrm{II})$ peak at $8985 \mathrm{eV}$ ( $1 s$ to $3 d$ electron transition), which is similar to that of the reference copper(II) phthalocyanine $(\mathrm{PcCu})$, thus confirming the presence of $\mathrm{Cu}-\mathrm{N}$ in $\mathrm{PcCu}-\mathrm{O}_{8}-\mathrm{Zn}^{40,41}$. Generally, two characteristic signals are observed in the $\mathrm{Zn}$ XANES spectra including the pre-edge peak at around $9660 \mathrm{eV}$ and the main absorption peak at $9660-9680 \mathrm{eV}$, which correspond to the electron transition from $1 s$ to $3 d$ (typically found for the transition metal $\mathrm{Zn}$ ) and the $1 s$ to $4 p$ electronic transition, 
a

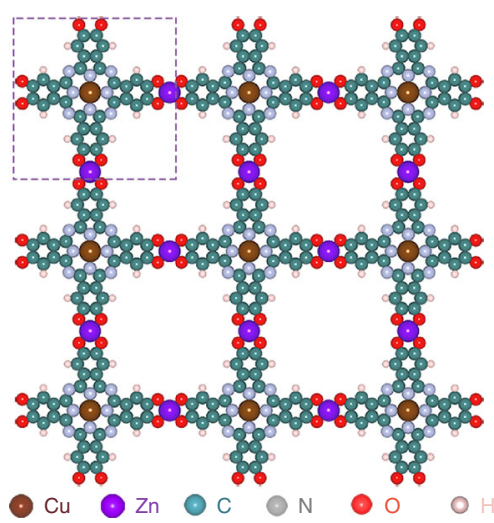

c

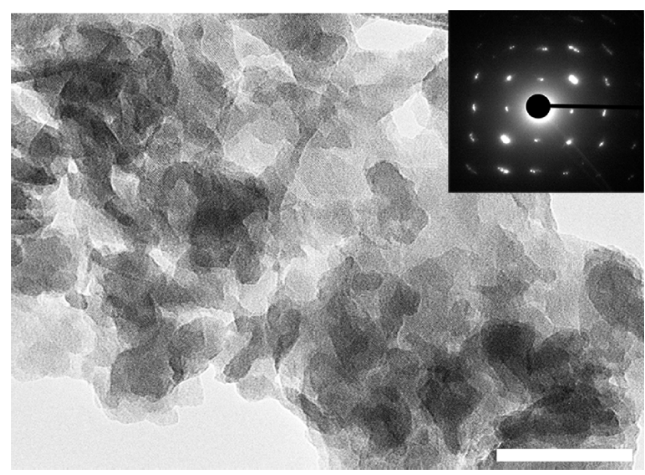

e

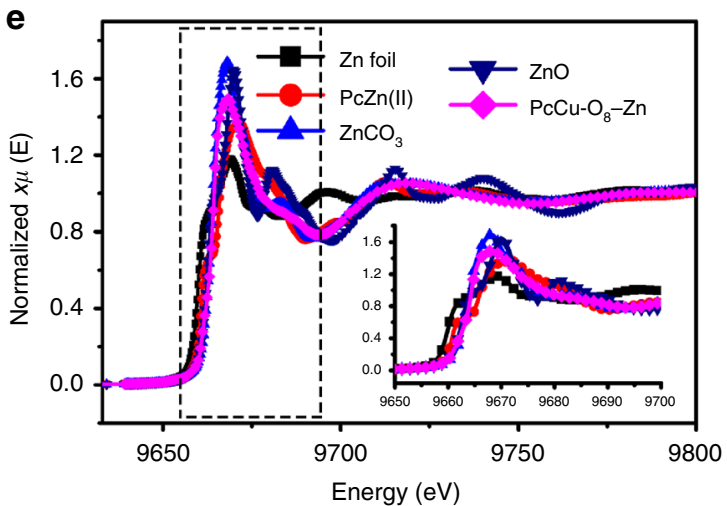

b

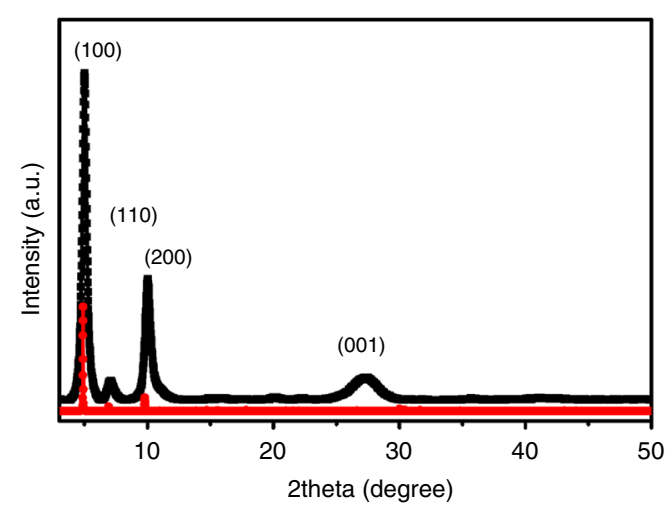

d

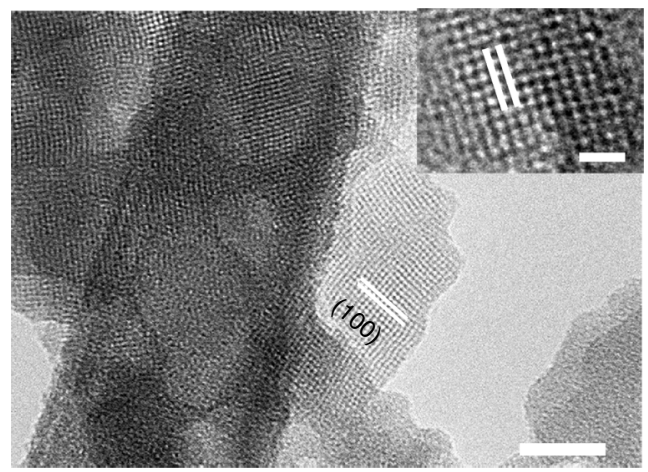

f

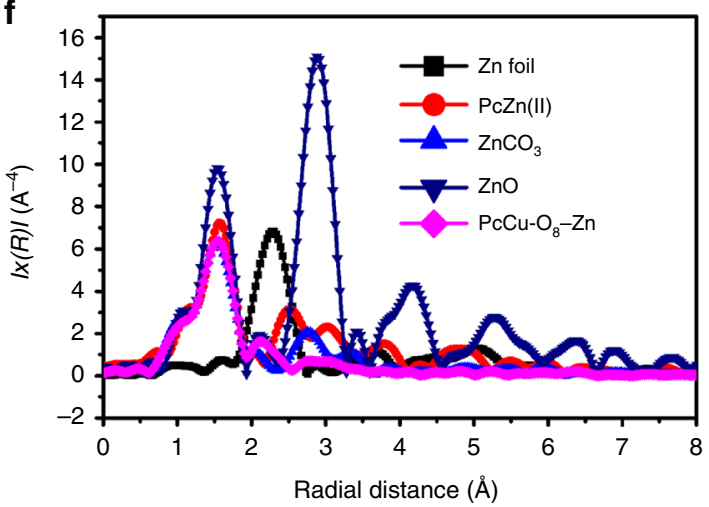

Fig. 2 Structure and morphology of $\mathbf{P c C u}-\mathbf{O}_{\mathbf{8}}-\mathbf{Z n}$. a Schematic structure of $\mathrm{PcCu}-\mathrm{O}_{8}-\mathrm{Zn}$ (the dashed rectangular indicates the unit cell). $\mathbf{b}$ Experimental (black square dot line) and calculated (red circle dot line) XRD patterns of $\mathrm{PcCu}-\mathrm{O}_{8}-\mathrm{Zn}$. c TEM image of PcCu- $\mathrm{O}_{8}-\mathrm{Zn}$ sample (inset: selected area electron diffraction pattern), Scale bar: $60 \mathrm{~nm}$. d HR-TEM image of PcCu- $\mathrm{O}_{8}-\mathrm{Zn}$ sample. Scale bar: $20 \mathrm{~nm}$ (inset: $5 \mathrm{~nm}$ ). e Zn K-edge XANES spectra for Zn foil, $\mathrm{ZnO}, \mathrm{ZnCO}_{3}, \mathrm{PcZn}(\mathrm{II})$ and $\mathrm{PcCu}-\mathrm{O}_{8}-\mathrm{Zn}$. Inset: the enlarged figure of the XANES spectra between 9650 and 9700 eV. f Fourier transform EXAFS of Zn foil, $\mathrm{ZnO}, \mathrm{ZnCO}_{3}, \mathrm{PcZn}$ and $\mathrm{PcCu}-\mathrm{O}_{8}-\mathrm{Zn}$.

respectively ${ }^{42}$. As shown in Fig. 2e, compared to $\mathrm{Zn}$ foil, the preedge peak signal at $9660 \mathrm{eV}$ is not detected in the $\mathrm{Zn} \mathrm{K}$-edge spectrum of $\mathrm{PcCu}-\mathrm{O}_{8}-\mathrm{Zn}$ due to the full occupied $3 d$ orbital of $\mathrm{Zn}^{2+}$, therefore excluding the existence of $\mathrm{Zn}(0)$ in $\mathrm{PcCu}_{-}-\mathrm{O}-\mathrm{Zn}$. In addition, $\mathrm{PcCu}-\mathrm{O}_{8}-\mathrm{Zn}$ also shows a main peak at $9665 \mathrm{eV}$ similar to the $\mathrm{ZnCO}_{3}$ and $\mathrm{ZnO}$ (Fig. 2e), which suggests the oxidation valence of $\mathrm{Zn}$ atom as +2 in $\mathrm{PcCu}-\mathrm{O}_{8}-\mathrm{Zn}^{42}$. Figure $2 \mathrm{f}$ displays the radial structure functions of $\mathrm{PcCu}_{\mathrm{C}} \mathrm{O}_{8}-\mathrm{Zn}$ and clearly demonstrates the characteristic $\mathrm{Zn}-\mathrm{O}$ coordination in $\mathrm{PcCu}-\mathrm{O}_{8^{-}}$ $\mathrm{Zn}$ with intensive peak at around $1.55 \AA$. The absence of obvious structural peaks and the diminishment of the signal at $2.27 \AA$ in Fig. $2 \mathrm{f}$ reveal that no heavy backscattering atoms $(\mathrm{Zn})$ are bound to $\mathrm{Zn}$ sites in $\mathrm{PcCu}-\mathrm{O}_{8}-\mathrm{Zn}^{43,44}$. Therefore, the XANES and EXAFS spectra of $\mathrm{PcCu}_{-}-\mathrm{O}_{8}-\mathrm{Zn}$ together with the contrast experiments provide solid proof for the existence of square planar complexes via the coordination of $\mathrm{PcCu}(\mathrm{II})-(\mathrm{OH})_{8}$ to $\mathrm{Zn}$ (II) ions.

Low-pressure $\mathrm{N}_{2}$ sorption was measured to evaluate the porous properties of $\mathrm{PcCu}_{-} \mathrm{O}_{8}-\mathrm{Zn}$ (Supplementary Fig. 13). The Brunauer Emmett Teller surface area was measured to be $378 \mathrm{~m}^{2} \mathrm{~g}^{-1}$. The pore size distribution indicates its abundant micropores $(1.4 \mathrm{~nm})$ and mesopores $(6 \mathrm{~nm})$, which can be favorable for the mass transport during the catalytic process ${ }^{28}$.

$\mathrm{CO}_{2} \mathrm{RR}$ activity evaluation. The electrocatalytic $\mathrm{CO}_{2} \mathrm{RR}$ activity of $\mathrm{PcCu}-\mathrm{O}_{8}-\mathrm{Zn}$ was evaluated in a two-compartment electrochemical cell in $0.1 \mathrm{M} \mathrm{KHCO}_{3}$ aqueous electrolyte. The $\mathrm{PcCu}^{-} \mathrm{O}_{8}$ $\mathrm{Zn} /$ carbon nanotube $(\mathrm{CNT})$ composite with a weight ratio of $2: 1$ (details provided in Methods section) was loaded on carbon 
a

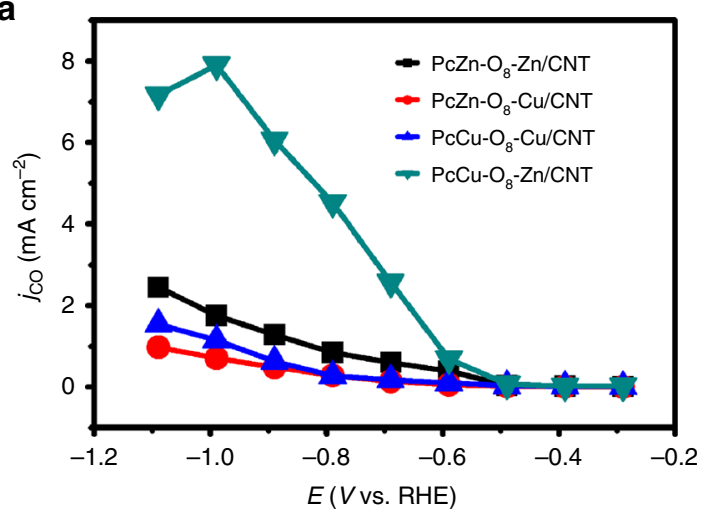

C

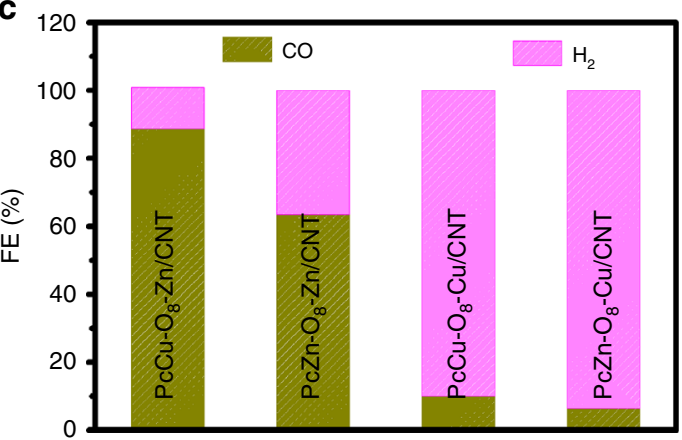

b

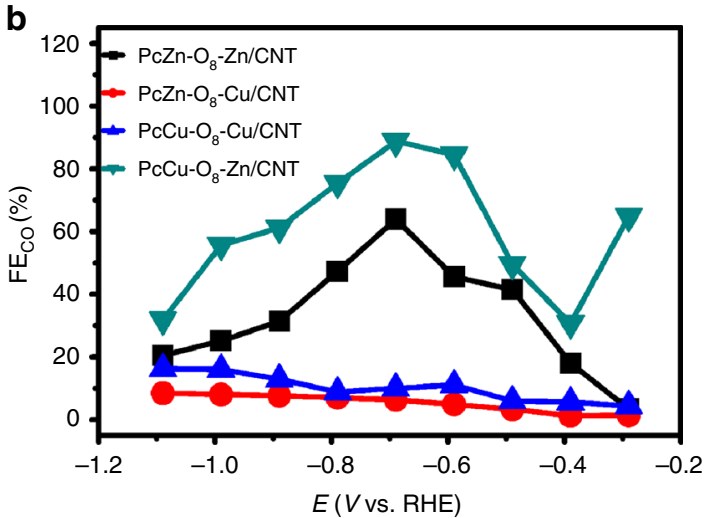

d

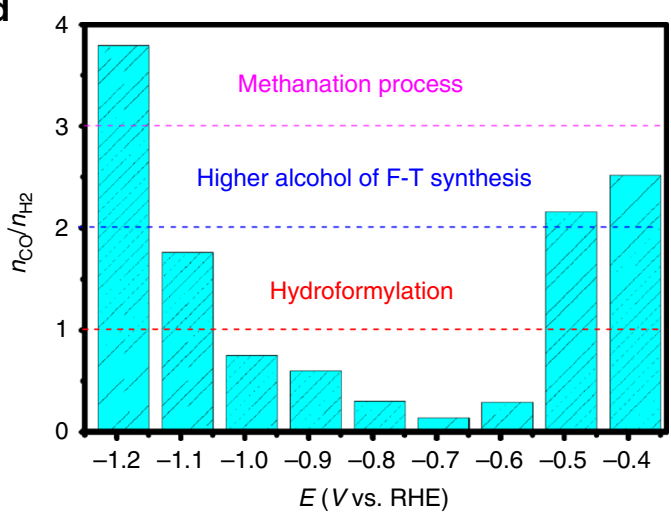

e

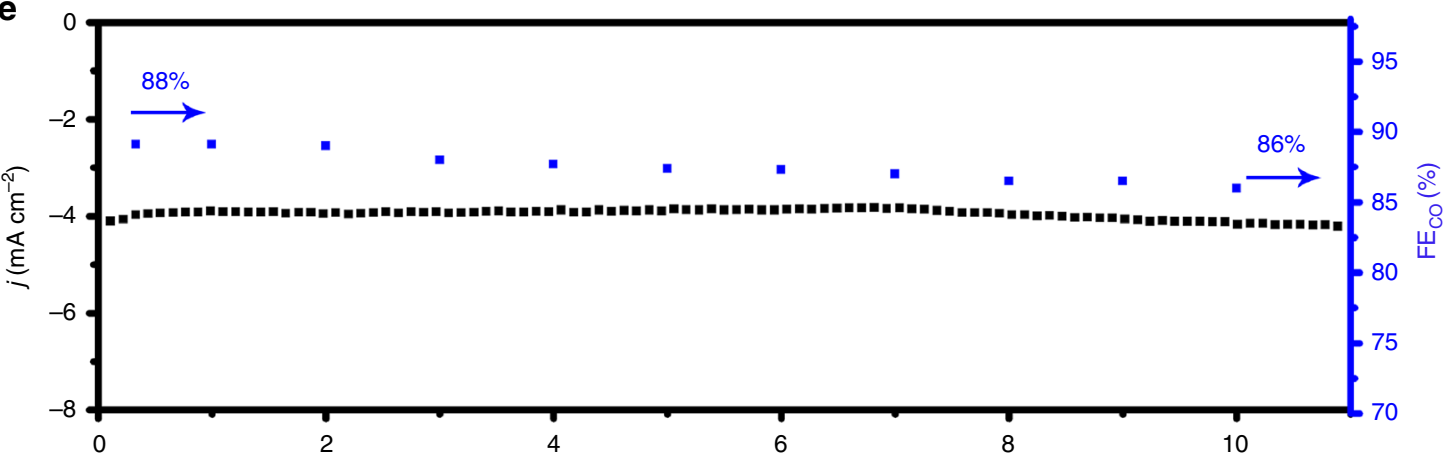

$t$ (h)

Fig. $3 \mathbf{C O}_{2}$ RR performance. a Partial current and $\mathbf{b}$ Faradaic efficiency of $\mathrm{CO}$ for PcCu-O $-\mathrm{O} n / \mathrm{CNT}, \mathrm{PcCu}-\mathrm{O}_{8}-\mathrm{Cu} / \mathrm{CNT}, \mathrm{PcZn}-\mathrm{O}_{8}-\mathrm{Zn} / \mathrm{CNT}$ and PcZn-O ${ }_{8}-$ $\mathrm{Cu} / \mathrm{CNT}$ at different potentials. $\mathbf{c}$ Faradaic efficiency of $\mathrm{CO}$ and $\mathrm{H}_{2}$ for $\mathrm{PcCu}-\mathrm{O}_{8}-\mathrm{Zn} / \mathrm{CNT}, \mathrm{PcCu}-\mathrm{O}_{8}-\mathrm{Cu} / \mathrm{CNT}, \mathrm{PcZn}-\mathrm{O}_{8}-\mathrm{Zn} / \mathrm{CNT}$ and $\mathrm{PcZn}-\mathrm{O}_{8}-\mathrm{Cu} / \mathrm{CNT}$ at $-0.7 \mathrm{~V}$ vs. RHE. d Molar $\mathrm{H}_{2} / \mathrm{CO}$ ratio at different applied potentials of $\mathrm{PcCu}-\mathrm{O}_{8}-\mathrm{Zn} / \mathrm{CNT}$. e Amperometry ( $i \sim t$ ) stability and the according Faradaic efficiency for $\mathrm{CO}$ of $\mathrm{PcCu}-\mathrm{O}_{8}-\mathrm{Zn} / \mathrm{CNT}$ at $-0.7 \mathrm{~V}$ vs. RHE in $\mathrm{CO}_{2}$-saturated $0.1 \mathrm{M} \mathrm{KHCO}_{3}$.

paper, which was contacted as the working electrode. The contrast composite samples of 2D $c$-MOFs/CNT (PcZn-O $-\mathrm{Zn} / \mathrm{CNT}$, $\mathrm{PcZn}-\mathrm{O}_{8}-\mathrm{Cu} / \mathrm{CNT}$ and $\left.\mathrm{PcCu}-\mathrm{O}_{8}-\mathrm{Cu} / \mathrm{CNT}\right)$ were also synthesized (details in Supplementary Information, Supplementary Figs. 14-17) and evaluated for electrocatalytic $\mathrm{CO}_{2} \mathrm{RR}$ activity. Cyclic voltammetry $(\mathrm{CV})$ experiments revealed increased current densities for $\mathrm{PcCu}-\mathrm{O}_{8}-\mathrm{Zn} / \mathrm{CNT}$ in $\mathrm{CO}_{2}$-saturated media compared to Ar-saturated electrolyte (Supplementary Fig. 18), demonstrating its feasibility for $\mathrm{CO}_{2} \mathrm{RR}$. To verify that the currents originate from the catalytic $\mathrm{CO}_{2} \mathrm{RR}$, constant potential electrolysis was performed. The products were detected via gas chromatography (GC) and nuclear magnetic resonance (NMR) measurements. The results indicate that only gaseous $\left(\mathrm{H}_{2}\right.$ and $\left.\mathrm{CO}\right)$ products were generated at the applied potentials with total Faradaic efficiency of $99 \pm 2.2 \%$ (Supplementary Figs. 19-21). The resultant $\mathrm{CO}_{2} \mathrm{RR}$ catalytic performance including the maximum $\mathrm{CO}$ efficiency and the molar $\mathrm{CO} / \mathrm{H}_{2}$ ratio suggested strong dependence on the type of metal centers and applied potential (Fig. 3a, b and Supplementary Fig. 20). Among the synthesized 2D c-MOFs/CNT hybrids, the $\mathrm{PcCu}-\mathrm{O}_{8}-\mathrm{Zn} / \mathrm{CNT}$ sample yielded the highest partial current density for $\mathrm{CO}\left(j_{\mathrm{CO}}\right)$ and the highest corresponding Faradic efficiency toward $\mathrm{CO}\left(\mathrm{FE}_{\mathrm{co}}\right)$ over the investigated potential range (Fig. 3a, b), indicating superiority of the $\mathrm{ZnO}_{4}$ sites for selective conversion of $\mathrm{CO}_{2}$ to $\mathrm{CO}$ over $\mathrm{ZnN}_{4}, \mathrm{CuN}_{4}$ and $\mathrm{CuO}_{4}$ centers, which is also supported by the DFT calculations (Fig. 1). Notably, $j_{\mathrm{CO}}$ for $\mathrm{PcCu}-\mathrm{O}_{8}-\mathrm{Zn} / \mathrm{CNT}$ showed a maximum value at $-1.0 \mathrm{~V}$ vs. $\mathrm{RHE}$, while $\mathrm{H}_{2}$ generation $\left(j_{\mathrm{H} 2}\right)$ displayed a steady rise with the increased overpotential (Supplementary Fig. 20a). This observation can be attributed to the competitive reactivity between the $\mathrm{CO}_{2} \mathrm{RR}$ and $\mathrm{HER}$ as well as the limitation 
of the transport of $\mathrm{CO}_{2}$ to the catalytic sites ${ }^{45}$. At $-0.7 \mathrm{~V}$ vs. RHE, the $\mathrm{FE}_{\mathrm{co}}$ for $\mathrm{PcCu}-\mathrm{O}_{8}-\mathrm{Zn} / \mathrm{CNT}$ reached up to $88 \%$, which is significantly higher than that of $\mathrm{PcZn}_{\mathrm{C}} \mathrm{O}-\mathrm{Zn} / \mathrm{CNT}$ (63\%), PcZn$\mathrm{O}_{8}-\mathrm{Cu} / \mathrm{CNT}(6 \%)$, and $\mathrm{PcCu}-\mathrm{O}_{8}-\mathrm{Cu} / \mathrm{CNT}(10 \%)$ and the other reported $\mathrm{Zn}$ - and MOF-based electrocatalysts (up to $\sim 80 \%$, seen in Supplementary Table 8$)^{13,18}$. Although $\mathrm{CuN}_{4}$ is more efficient for HER compared to $\mathrm{ZnN}_{4}$ based on theoretical calculations, $\mathrm{PcCu}-\mathrm{O}_{8}-\mathrm{Zn} / \mathrm{CNT}$ consisting of $\mathrm{CuN}_{4}$ and $\mathrm{ZnO}_{4}$ complexes still shows higher $\mathrm{FE}_{\mathrm{co}}$ than that of $\mathrm{PcZn}-\mathrm{O}_{8}-\mathrm{Zn} / \mathrm{CNT}$ comprising $\mathrm{ZnN}_{4}$ and $\mathrm{ZnO}_{4}$ complexes. This points to the synergistic catalytic effects between $\mathrm{CuN}_{4}$ and $\mathrm{ZnO}_{4}$ in selective electroreduction of $\mathrm{CO}_{2}$ to $\mathrm{CO}$. In addition, $\mathrm{PcCu}-\mathrm{O}_{8}-\mathrm{Zn} / \mathrm{CNT}$ also shows a high TOF of $0.39 \mathrm{~s}^{-1}$, which is superior to other MOFs and Zn-related electrocatalysts (Supplementary Table 8). The molar ratio of the syngas $\mathrm{CO} / \mathrm{H}_{2}$ catalytically generated by the $2 \mathrm{D} c$-MOFs could be additionally controlled via the applied potentials. As shown in Fig. 3d, the molar $\mathrm{H}_{2} / \mathrm{CO}$ ratio for the $\mathrm{PcCu}-\mathrm{O}_{8}-\mathrm{Zn} / \mathrm{CNT}$ system could be tuned from around 1:7 to $4: 1$ by increasing the applied potential from -0.4 to $-1.2 \mathrm{~V}$ vs. RHE.

To elucidate the kinetics of these MOFs toward the catalytic $\mathrm{CO}_{2} \mathrm{RR}$, Tafel slopes were derived (Supplementary Fig. 22a). PcCu$\mathrm{O}_{8}$ - Zn/CNT exhibited the lowest Tafel slope $\left(125 \mathrm{mV} \mathrm{dec}^{-1}\right)$ toward the $\mathrm{CO}$ production compared to $\mathrm{PcZn}-\mathrm{O}_{8}-\mathrm{Zn} / \mathrm{CNT}$ (145 $\left.\mathrm{mV} \mathrm{dec}{ }^{-1}\right), \mathrm{PcZn}_{-} \mathrm{O}_{8}-\mathrm{Cu} / \mathrm{CNT}\left(223 \mathrm{mV} \mathrm{dec}{ }^{-1}\right)$ and $\mathrm{PcCu}-\mathrm{O}_{8}-\mathrm{Cu} /$ CNT $\left(280 \mathrm{mV} \mathrm{dec}^{-1}\right)$, confirming its faster kinetics. Electrochemical impedance spectroscopy results indicate that $\mathrm{PcCu}-\mathrm{O}_{8}-\mathrm{Zn} /$ CNT exhibits smaller resistance and faster electron kinetics than those of other as-synthesized 2D c-MOFs/CNT samples (Supplementary Fig. 22b). Besides, the $\mathrm{PcCu}-\mathrm{O}_{8}-\mathrm{Zn} / \mathrm{CNT}$ system presents long-term catalytic durability. The high $\mathrm{FE}_{\mathrm{CO}}(86 \%)$ and current density were maintained over the course of $10 \mathrm{~h}$ of operation at $-0.7 \mathrm{~V}$ vs. RHE (Fig. 3e). No obvious changes of morphology and structure (Supplementary Fig. 23) were observed in SEM image, XRD pattern, Raman and FR-IR spectra of $\mathrm{PcCu}-\mathrm{O}_{8}-\mathrm{Zn} / \mathrm{CNT}$ after the $\mathrm{CO}_{2} \mathrm{RR}$ long-term testing, demonstrating the high stability of $\mathrm{PcCu}-\mathrm{O}_{8}-\mathrm{Zn} / \mathrm{CNT}$ during electrocatalytic $\mathrm{CO}_{2}$ conversion.

Unveiling the active sites. Operando XAS measurement was employed to gain insight into the valence state and coordination structure of $\mathrm{Cu}$ and $\mathrm{Zn}$ in the $\mathrm{PcCu}-\mathrm{O}_{8}-\mathrm{Zn} / \mathrm{CNT}$ under the $\mathrm{CO}_{2} \mathrm{RR}$ turnover condition (Fig. $4 \mathrm{a}-\mathrm{d}$ and Supplementary Fig. 24). As shown in Fig. 4a, a typical pre-edge signal of $\mathrm{Zn}(0)$ at around $9660 \mathrm{eV}$ is not observed in the $\mathrm{Zn} K$-edge XANES spectra for all $\mathrm{PcCu}-\mathrm{O}_{8}-\mathrm{Zn} / \mathrm{CNT}$ samples ${ }^{42,43}$. This excludes the generation of metallic $\mathrm{Zn}$ in $\mathrm{PcCu}-\mathrm{O}_{8}-\mathrm{Zn} / \mathrm{CNT}$ electrocatalyst during the $\mathrm{CO}_{2} \mathrm{RR}$ process. Importantly, the main absorption peak at $9665 \mathrm{eV}$ was not shifted in the $\mathrm{Zn} K$-edge XANES spectra of $\mathrm{PcCu}-\mathrm{O}_{8}-\mathrm{Zn} / \mathrm{CNT}$ (Fig. 4a) as the applied potential was decreased to -0.4 (red circle dot curve) and $-0.7 \mathrm{~V}$ (blue diamond dot curve) vs. RHE, respectively, and then increased back (indigo triangle dot curve) to the initial (black square dot curve) open circuit voltage $(\mathrm{OCV})$. The results reveal that the oxidation state of $\mathrm{Zn}(\mathrm{II})$ in $\mathrm{PcCu}-\mathrm{O}_{8}-\mathrm{Zn} / \mathrm{CNT}$ was maintained throughout the catalytic process, which can be explained by the fact that the $\mathrm{Zn}(\mathrm{II})$ already has a full $3 d$ electron shell ${ }^{46}$. In addition, the preedge peak at $8985 \mathrm{eV}$ and the main absorption peak at $8998 \mathrm{eV}$ in the $\mathrm{Cu} \mathrm{K}$-edge XANES spectra of $\mathrm{PcCu}-\mathrm{O}_{8}-\mathrm{Zn} / \mathrm{CNT}$ were not varied upon changing the applied potential, which indicates that the valence state of $\mathrm{Cu}$ (II) was not changed during the $\mathrm{CO}_{2} \mathrm{RR}$ process. Notably, the missing pre-edge peak at $8980 \mathrm{eV}$ in $\mathrm{Cu} \mathrm{K}$ edge XANES spectra of all $\mathrm{PcCu}_{-} \mathrm{O}_{8}-\mathrm{Zn} / \mathrm{CNT}$ samples further confirms that no metallic $\mathrm{Cu}$ was generated at the $\mathrm{PcCu}-\mathrm{O}_{8}-\mathrm{Zn} /$ CNT electrode under electrolysis condition (Fig. 4b).

To monitor the local coordination environment changes, in situ EXAFS measurements were performend. As the applied potential was performed for one cycle, the peak at $1.55 \AA$ assigned as $\mathrm{Zn}-\mathrm{O}$ bond length in $\mathrm{PcCu}_{-}-\mathrm{O}-\mathrm{Zn} / \mathrm{CNT}$ was not shifted (Fig. 4c). Meanwhile, the peak intensity presents a negligible decrease (black square dot and indigo triangle dot curves in Fig. 4c), which is possibly due to the interaction of the reaction intermediates and the $\mathrm{ZnO}_{4}$ sites during the catalytic process, such as ${ }^{*} \mathrm{H},{ }^{*} \mathrm{COOH},{ }^{*} \mathrm{CO}$ and so ${ }^{43}$. Therefore, the above in situ EXAFS results reveal no obvious change in $\mathrm{Zn}$ coordination number and bond length of $\mathrm{Zn}-\mathrm{O}$ for $\mathrm{PcCu}-\mathrm{O}_{8^{-}}$ $\mathrm{Zn} / \mathrm{CNT}$ under the electrolysis condition. Furthermore, the characteristic signal of $\mathrm{Zn}-\mathrm{Zn}$ bonding at $2.27 \AA$ does not appear in the EXAFS spectra of all the $\mathrm{PcCu}-\mathrm{O}_{8}-\mathrm{Zn} / \mathrm{CNT}$ samples, again excluding the formation of metallic $\mathrm{Zn}$ or $\mathrm{Zn}$ cluster at $\mathrm{PcCu}-\mathrm{O}_{8}-\mathrm{Zn} / \mathrm{CNT}$ catalyst throughout $\mathrm{CO}_{2} \mathrm{RR}$ process. Regarding the $\mathrm{CuN}_{4}$ complexes, no obvious change of the $\mathrm{Cu}-\mathrm{N}$ coordination peak at $1.54 \AA$ was detected in the $\mathrm{Cu} \mathrm{K}$-edge EXAFS spectra of $\mathrm{PcCu}-\mathrm{O}_{8}-\mathrm{Zn} / \mathrm{CNT}$ (Fig. 4d) upon performing the potential in one cycle. Additionally, no obvious signal of $\mathrm{Cu}$ - Cu bonds was observed at $2.23 \AA$, which demonstrates that no heavy backscattering atoms $(\mathrm{Cu})$ are bound to $\mathrm{Cu}$ sites in all $\mathrm{PcCu}-\mathrm{O}_{8}-\mathrm{Zn}$ samples. Therefore, the operando XAS results fully prove that the well-defined sites $\left(\mathrm{ZnO}_{4}\right.$ and $\left.\mathrm{CuN}_{4}\right)$ act as stable catalytic centers during the $\mathrm{CO}_{2} \mathrm{RR}$ process, while no metals or metal clusters form via the reduction of high-valence metal centers.

Next, operando SEIRA spectroelectrochemistry was employed to elucidate the electrocatalytic mechanism of the 2D c-MOF catalysts. The $2 \mathrm{D}$ c-MOFs were evenly deposited as a closed film onto a nanostructured Au surface, which acted as IR signal amplifier. SEIRA spectra were recorded at different potentials covering a broad potential window. SEIRA difference spectra taken under turnover conditions were derived using the spectrum of the respective system at $-0.6 \mathrm{~V}$ vs. $\mathrm{Ag} / \mathrm{AgCl}$ (Fig. $4 \mathrm{e}, \mathrm{f}$ ). The SEIRA difference spectra of $\mathrm{PcZn}-\mathrm{O}_{8}-\mathrm{Cu} / \mathrm{CNT}$ and $\mathrm{PcCu}-\mathrm{O}_{8}-\mathrm{Zn} /$ CNT show distinct features that likely arise from their intrinsically different reactivities (Supplementary Fig. 25). Upon lowering the potential, a negative band at $2343 \mathrm{~cm}^{-1}$ assigned to dissolved $\mathrm{CO}_{2}(\mathrm{~g})$ was observed. This band was found to decrease with decreased potential indicating the consumption of $\mathrm{CO}_{2}$ near the surface in the catalytic process ${ }^{45}$. Strong positive bands in the region of $1660-1640 \mathrm{~cm}^{-1}$ were observed in both cases and attributed to the changes of the interfacial $\mathrm{H}_{2} \mathrm{O}$, which accumulated in the MOFs due to catalysis or increasing negative polarization of the electrode. The high-frequency bands above $1800 \mathrm{~cm}^{-1}$ typically arise from metal bound species. Specifically, the bands located in the higher frequency region at 1933 and $2071 \mathrm{~cm}^{-1}$ were assigned to $\mathrm{CO}$ bound to the $\mathrm{CuN}_{4}$ and $\mathrm{CuO}_{4}$ centers, respectively (Fig. $4 \mathrm{e}, \mathrm{f})^{47}$. The shift of the $v(\mathrm{CO})$ mode could arise from the different electronic properties of $\mathrm{Cu}$ metal in the $\mathrm{N}_{4}$ and $\mathrm{O}_{4}$ frame, respectively. In this respect, $\mathrm{CuN}_{4}$ centers can stabilize the $\mathrm{CO}$ via $\pi$ backbonding leading to drastically lowered $v(\mathrm{CO}) s$, while $\mathrm{CO}$ bound to $\mathrm{Cu}$ and oxide-derived $\mathrm{Cu}$ surfaces has been reported above $2000 \mathrm{~cm}^{-1,47,48}$. The strong band centered at $1851 \mathrm{~cm}^{-1}$ for the $\mathrm{PcZn}-\mathrm{O}_{8}-\mathrm{Cu} / \mathrm{CNT}$ system matches the frequency for (isolated) $\mathrm{Cu}-\mathrm{H}$ and is thus assigned to the $\mathrm{Cu}-\mathrm{H}$ intermediate formed at the $\mathrm{CuO}_{4}$ nodes in the HER cascade $^{47,49}$. The particularly high intensity of this band suggests a dominating HER process over $\mathrm{CO}_{2} \mathrm{RR}$ at $\mathrm{PcZn}-\mathrm{O}_{8}-\mathrm{Cu} / \mathrm{CNT}$ in $\mathrm{CO}_{2}$-saturated solution. This interpretation is consistent with the electrocatalytic results (Supplementary Fig. 20), revealing that the $\mathrm{PcZn}-\mathrm{O}_{8}-\mathrm{Cu} / \mathrm{CNT}$ system shows high selectivity for $\mathrm{H}_{2}(>90 \%)$ over the complete potential range in $\mathrm{CO}_{2}$-saturated electrolyte. In contrast, $\mathrm{Cu}-\mathrm{H}$ is not observed at the $\mathrm{CuN}_{4}$ units of the $\mathrm{PcCu}-\mathrm{O}_{8^{-}}$ $\mathrm{Zn} / \mathrm{CNT}$ systems. This may be due to low accumulation of the $\mathrm{Cu}-\mathrm{H}$ species during catalysis, which could result from the fast proton transfer kinetics at $\mathrm{CuN}_{4}$ complexes to $\mathrm{ZnO}_{4}$ sites and 

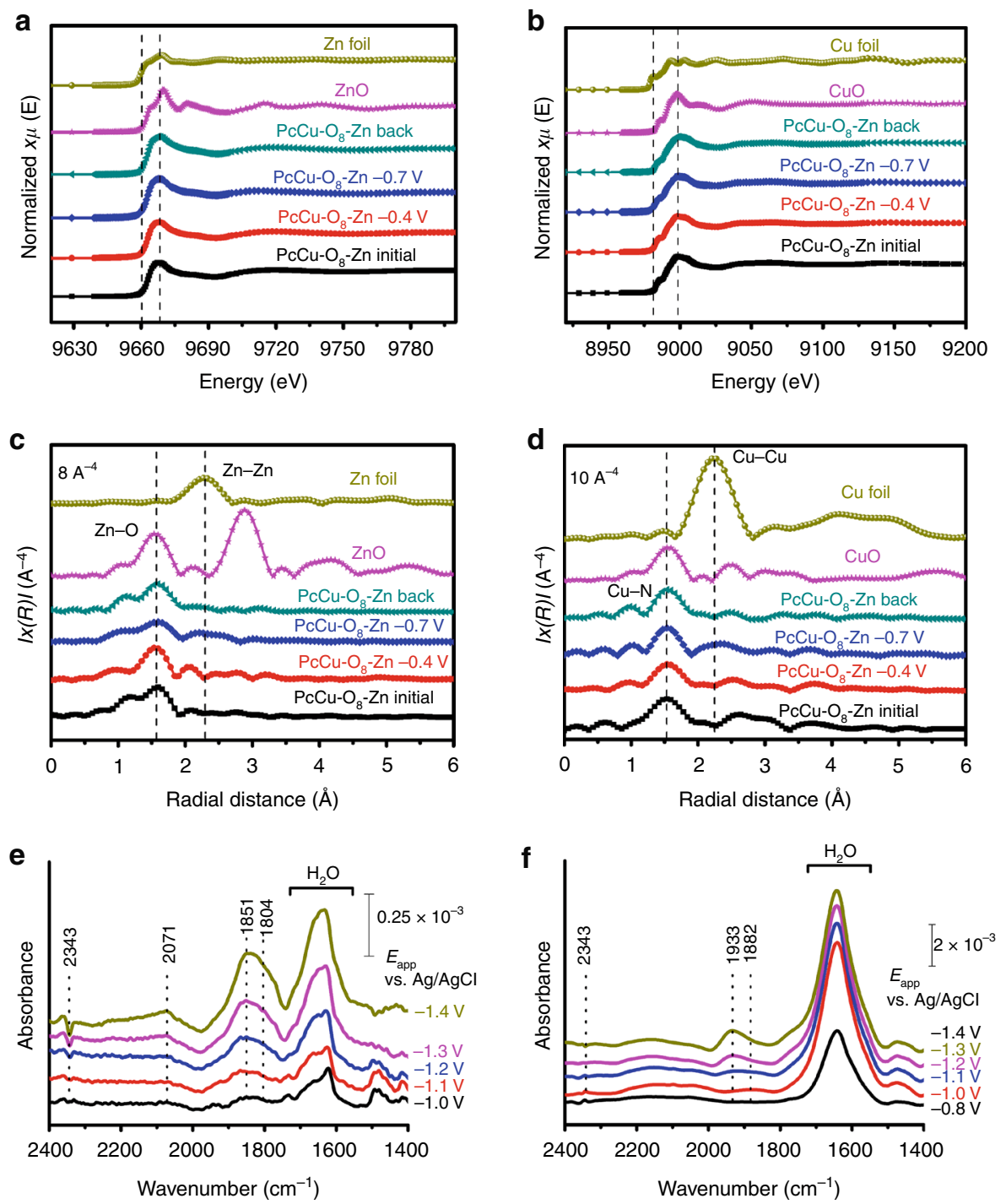

Fig. 4 Operando XAS and SEIRA measurement under electrolysis. a Zn K-edge XANES spectra of Zn foil, ZnO, PcCu-O 8 -Zn samples. b Cu K-edge XANES spectra of $\mathrm{Cu}$ foil, $\mathrm{CuO}, \mathrm{PcCu}-\mathrm{O}_{8}-\mathrm{Zn}$ samples. c Zn K-edge Fourier transform EXAFS spectra of $\mathrm{Zn}$ foil, ZnO and PcCu-O $-\mathrm{Zn}$ samples. d Cu K-edge Fourier transform EXAFS spectra of $\mathrm{Cu}$ foil, $\mathrm{CuO}$ and $\mathrm{PcCu}_{-} \mathrm{O}_{8}-\mathrm{Zn}$ samples.e, $\mathbf{f}$ Operando SEIRA spectro-electrochemical analysis of $\mathrm{PcZn}-\mathrm{O}_{8}-\mathrm{Cu} / \mathrm{CNT}$ (e) and $\mathrm{PcCu}-\mathrm{O}_{8}-\mathrm{Zn} / \mathrm{CNT}$ (f) in $\mathrm{CO}_{2}$-saturated $0.1 \mathrm{M} \mathrm{KHCO}_{3}$. As reference, a SEIRA spectrum of the system at $-0.6 \mathrm{~V}$ vs. $\mathrm{Ag} / \mathrm{AgCl}$ was taken.

yield $\mathrm{H}_{2}$. Interestingly, no indication for $\mathrm{CO}$ binding to the $\mathrm{ZnO}_{4}$ nodes was found due to its too low transient concentration to be observed with our current SEIRA spectro-electrochemical setup. This can be explained by the weak binding energy between $\mathrm{ZnO}_{4}$ and $\mathrm{CO}$, which could facilitate a quick deliberation of the product and thus suggests fast $\mathrm{CO}_{2} \mathrm{RR}$ kinetics at the $\mathrm{ZnO}_{4}$ complexes in $\mathrm{PcCu}-\mathrm{O}_{8}-\mathrm{Zn} / \mathrm{CNT}$.

\section{Discussion}

To obtain further insight into the reactivity of 2D $c$-MOFs towards HER and $\mathrm{CO}_{2} \mathrm{RR}$, the calculated free energy profiles on $\mathrm{M} 1 O_{4}$ site at $U=0.55 \mathrm{~V}$ were analyzed (Fig. 5a). For HER, the Gibbs free energy values of the key intermediates $\left({ }^{*} \mathrm{H}\right)$ on $\mathrm{M} \mathrm{O}_{4}$ units are positive, with a minimum barrier of $0.7 \mathrm{eV}$, and therefore expected to be kinetically prohibited. However, the free energy values of $\mathrm{CO}_{2} \mathrm{RR}$ at the same equilibrium potential are negative, which reveals that the $\mathrm{CO}_{2} \mathrm{RR}$ at $\mathrm{MlO}_{4}$ site is thermodynamically downhill. It further verifies the favorable $\mathrm{CO}_{2} \mathrm{RR}$ process at $\mathrm{MlO}_{4}$ complexes of $2 \mathrm{D} c$-MOFs. Although the $\mathrm{CuN}_{4}$ complexes show the lowest energy barriers for $\mathrm{HER}, \mathrm{PcCu}-\mathrm{O}_{8}-\mathrm{Zn}$ still exhibits the lowest free energy for the generation of rate-determining ${ }^{*} \mathrm{COOH}$ intermediate as compared to the other $2 \mathrm{D} c$-MOFs during $\mathrm{CO}_{2} \mathrm{RR}$ catalysis. This establishes the synergetic effect of $\mathrm{CuN}_{4}$ and $\mathrm{ZnO}_{4}$ in enhancing the $\mathrm{CO}_{2} \mathrm{RR}$ activity. A proposed synergistic catalytic scheme is presented in Fig. 5b. $\mathrm{CuN}_{4}$ complexes attract numerous electrons and $\mathrm{H}_{2} \mathrm{O}$ toward producing abundant protons, wherein protons are partially transformed into molecular $\mathrm{H}_{2}$ and partially transferred to $\mathrm{ZnO}_{4}$ complexes. Simultaneously, the adsorbed $\mathrm{CO}_{2}$ on $\mathrm{ZnO}_{4}$ complexes is reduced to ${ }^{*} \mathrm{COOH}$ by coupling with these protons/ electrons from the $\mathrm{CuN}_{4}$ sites and electrode/electrolyte, and subsequently the resultant ${ }^{*} \mathrm{COOH}$ will be transformed into $* \mathrm{CO}$ intermediate by a further charge transfer step (one electron and one proton). The desorption of ${ }^{*} \mathrm{CO}$ results in the final $\mathrm{CO}$ product. As a result, the kinetics of $\mathrm{CO}_{2} \mathrm{RR}$ on $\mathrm{ZnO}_{4}$ is greatly enhanced in $\mathrm{PcCu}_{8}-\mathrm{O}_{8}-\mathrm{Zn} 2 \mathrm{D}$-MOF.

In summary, we have synthesized a layered 2D c-MOF (PcCu$\left.\mathrm{O}_{8}-\mathrm{Zn}\right)$ with bimetallic centers $\left(\mathrm{ZnO}_{4} / \mathrm{CuN}_{4}\right)$ capable of synergistic electroreduction of $\mathrm{CO}_{2}$ to $\mathrm{CO}$ based on the theory-guided design. The electrocatalytic results indicated that $\mathrm{PcCu}_{\mathrm{C}} \mathrm{O}_{8}-\mathrm{Zn}$ mixing with CNTs exhibited high $\mathrm{CO}_{2} \mathrm{RR}$ catalytic activity with high selectivity for $\mathrm{CO}$ conversion of $88 \%$, TOF of $0.39 \mathrm{~s}^{-1}$ and 

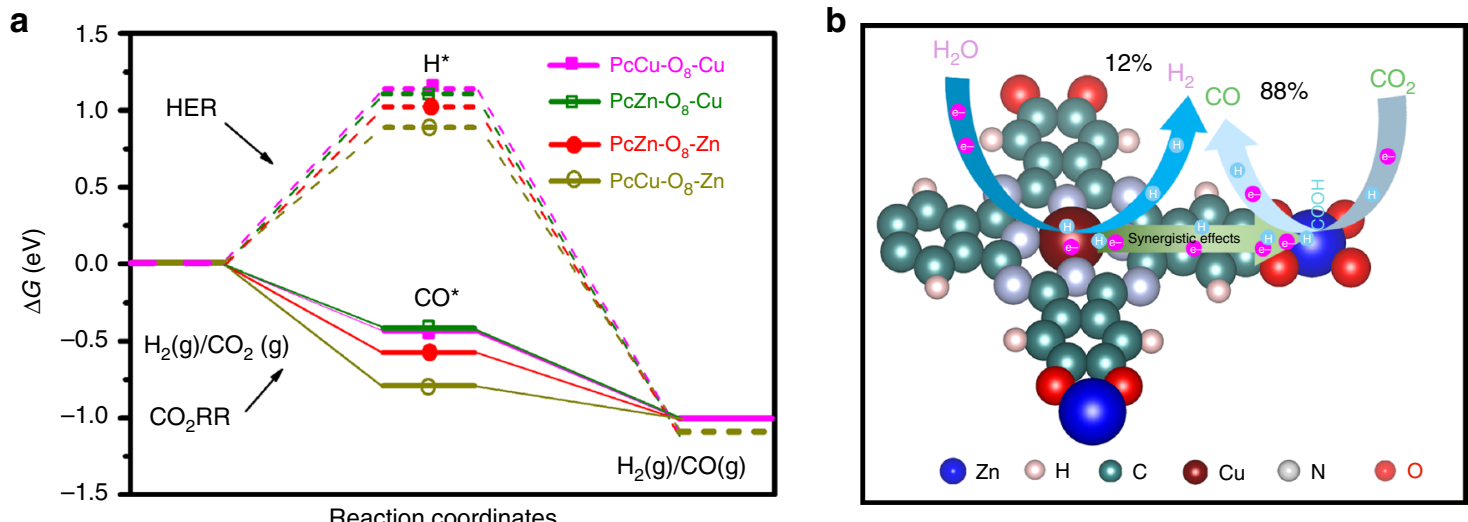

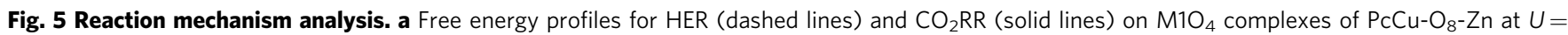
$0.55 \mathrm{~V}$. b Schematic HER and $\mathrm{CO}_{2} \mathrm{RR}$ reaction process of $\mathrm{PcCu}-\mathrm{O}_{8}-\mathrm{Zn}$.

long-term durability $(>10 \mathrm{~h})$, which is superior to the reported MOF- and Zn-based electrocatalysts. The molar $\mathrm{H}_{2} / \mathrm{CO}$ ratio could be rationally adjusted through varying the metal centers and applied catalytic potentials, beneficial for industrial applications. Theoretical calculation and the operando XAS and SEIRA analysis, as well as the control experiments suggested that the $\mathrm{CO}_{2} \mathrm{RR}$ takes place at the $\mathrm{ZnO}_{4}$ units while the $\mathrm{CuN}_{4}$ units promote the proton and electron transfer during the reaction process. Thus, the combination of $\mathrm{ZnO}_{4}$ and $\mathrm{CuN}_{4}$ complexes generates a synergetic effect, which contributes to the high $\mathrm{CO}_{2} \mathrm{RR}$ performance of $\mathrm{PcCu}-\mathrm{O}_{8}-\mathrm{Zn} / \mathrm{CNT}$. Our work demonstrates the capability of bimetallic $2 \mathrm{D} c$-MOFs as highly efficient electrocatalysts for promoting the $\mathrm{CO}_{2} \mathrm{RR}$, which is of importance for conductive MOFs design and their electrocatalysis application and also sheds light on the development of high-performance bimetal-heteroatom doped carbon electrocatalysts.

\section{Methods \\ Computational studies. The computational modeling of the reactants, inter- mediates and products, and reaction process involved in the reactions on 2D MOFs was performed by using DFT with the PBE exchange-correlation functional ${ }^{50}$, as implemented in the VASP code ${ }^{51,52}$. The total energies were converged within $10^{-6} \mathrm{eV} /$ cell. The cut-off energy for plane wave basis was set at $500 \mathrm{eV}$. The Brillouin zone of the supercells was sampled using $4 \times 4 \times 1$ Monkhorst-Pack grid of $k$-points. All calculations have been performed using the spin-polarized setup. Dispersion interactions were taken into account as proposed by Grimme within the DFT-D2 scheme ${ }^{53}$. More detail and relevant reference are provided in the} Supplementary Information.

Synthesis of $\mathbf{P c C u}-\mathbf{O}_{\mathbf{8}}-\mathbf{Z n}(\mathbf{C u})$. PcCu- $(\mathrm{OH})_{8}(0.005 \mathrm{mmol})$ was well dispersed into DMF (N,N-Dimethyformamide, $25 \mathrm{ml}$ ). After adding $2.2 \mathrm{ml}$ of $\mathrm{NH}_{3} \mathrm{H}_{2} \mathrm{O}$ (50\%), the mixture solution was diluted by $30 \mathrm{ml}$ of $\mathrm{H}_{2} \mathrm{O}$. After sonication for $5 \mathrm{~min}, 5 \mathrm{ml}$ of $\mathrm{M}(\mathrm{acac})_{2}(\mathrm{M}=\mathrm{Cu}, \mathrm{Zn}, 0.01 \mathrm{mmol})$ solution was added into the above mixture. This mixture was transferred into the autoclave and heated at $120^{\circ} \mathrm{C}$ for $40 \mathrm{~h}$. Finally, the solid was obtained by filtration, washing with DMF, $\mathrm{H}_{2} \mathrm{O}$ and acetone, and vacuum drying at room temperature. $\mathrm{PcM}-\mathrm{O}_{8}-\mathrm{M} 1 / \mathrm{CNT}(\mathrm{M}, \mathrm{M} 1=\mathrm{Cu}$ or $\mathrm{Zn}$ ) was synthesized with the similar procedure except that $15 \mathrm{mg}$ of CNT was mixed with the $\mathrm{PcCu}-(\mathrm{OH})_{8}$ precursor, wherein the ratio of $\mathrm{PcM}-\mathrm{O}_{8}-\mathrm{M} 1$ and $\mathrm{CNT}$ is around $2: 1$.

Characterization. Powder XRD measurements were collected on a PW1820 powder diffractometer (Phillips) using $\mathrm{Cu}-\mathrm{Ka}$ radiation $(\lambda=0.15418 \mathrm{~nm}, 40 \mathrm{kV}$, $30 \mathrm{~mA}$ ). TEM images were obtained using a Cs-corrected TEM (Carl Zeiss Libra 200) operated at $200 \mathrm{kV}$. SEM was recorded on Zeiss Gemini S4 500. Raman spectra were collected with a Renishaw 2000 model confocal microscopy Raman spectrometer with a CCD detector and a holographic notch filter at ambient conditions. FT-IR tests were performed on a Bruker Optics ALPHA-E spectrometer equipped with Attenuated Total Reflectance (ATR) sample holder. The porosity was detected by nitrogen sorption using a micromeritics ASAP 2020 analyzer. XPS spectra were collected with an ESCALAB MK II X-ray photoelectron spectrometer using an $\mathrm{Al} \mathrm{Ka}$ source. The rotating disk electrode (RDE) was performed on MSR electrode rotator (Pine Instrument Co.). The XAS and EXAFS data were collected at room temperature in transmission mode at beamline BL14W1 and BL15U1 of the Shanghai Synchrotron Radiation Facility (SSRF, China).

Electrode preparation. One milligram of catalyst was added into $100 \mu$ l of ethanol containing $10 \mu \mathrm{l}$ of Nafion solution (5\% in ethanol) and ultrasonically treated for $30 \mathrm{~min}$. And the catalyst ink was drop-casted onto carbon paper.

Electrochemical test. Before testing, the Nafion membrane (115) was treated in $\mathrm{H}_{2} \mathrm{O}_{2}$ solution (5\%) and pure water for $1 \mathrm{~h}$. And the carbon paper with loading catalyst, $\mathrm{Pt}$ mesh and $\mathrm{Ag} / \mathrm{AgCl}$ are used as the working, counter and reference electrode. Firstly, the electrolyte in the cathodic compartment was degassed by bubbling with Ar for at least $30 \mathrm{~min}$ for removal of oxygen, and then purged continuously with $\mathrm{CO}_{2} \cdot \mathrm{CO}_{2}$ gas was delivered into the cathodic compartment at a rate of $30.00 \mathrm{sccm}$ and was vented directly into the gas-sampling loop of a gas chromatograph. GC run was initiated every $20 \mathrm{~min}$. All reference electrodes are converted to the RHE reference scale using $E$ (vs. RHE) $=E(\mathrm{vs} . \mathrm{Ag} / \mathrm{AgCl})+0.197$ $\mathrm{V}+0.0591 \mathrm{~V} \times \mathrm{pH}$.

The partial current densities of $\mathrm{CO}$ and $\mathrm{H}_{2}$ production were calculated from the GC peak areas as follows:

$$
j_{\mathrm{CO} / \mathrm{H}_{2}}=v_{\mathrm{CO} / \mathrm{H}_{2}} \times \text { flow rate } \times \frac{2 F P_{0}}{R T} A^{-1},
$$

where $V_{\mathrm{CO}}$ and $V_{\mathrm{H} 2}$ are the volume concentration of $\mathrm{CO}$ and $\mathrm{H}_{2}$, respectively, $P_{0}$ is the standard atmospheric pressure ( $1.013 \mathrm{bar}), T$ is the absolute temperature $(273.15 \mathrm{~K}), F$ is Faradaic constant $\left(96,485 \mathrm{C} \mathrm{mol}^{-1}\right)$, and $A$ is the electrode area (1 $\mathrm{cm}^{2}$ ). Faradaic efficiencies for a given product were calculated by dividing these partial current densities by the total current density.

The liquid products were analyzed by NMR spectroscopy, in which $0.5 \mathrm{ml}$ of the electrolyte was mixed with $0.1 \mathrm{ml} \mathrm{D}_{2} \mathrm{O}$ and $0.05 \mu \mathrm{l}$ dimethyl sulfoxide (DMSO), wherein DMSO was serviced as an internal standard. The one-dimensional ${ }^{1} \mathrm{H}$ spectrum was measured with water suppression using a pre-saturation method.

Operando XAS measurement. Operando XANES and EXAFS experiments were carried out at the BL14W1 beamline of the Shanghai Synchrotron Radiation Facility (SSRF). All data were collected in fluorescence mode under applied potential controlled by CHI electrochemical workstation. A custom-designed cell (Supplementary Fig. 21) was used for the in situ XAS measurements, which was applied to the identical conditions as the real $\mathrm{CO}_{2} \mathrm{RR}$ testing. The X-ray energy was calibrated using a $\mathrm{Cu}$ metal foil and $\mathrm{Zn}$ metal foil.

Operando SEIRA spectro-electrochemistry. All measurements were conducted in aqueous $\mathrm{CO}_{2}$ saturated $0.1 \mathrm{M} \mathrm{KHCO}_{3}$. An FT-IR spectrometer (Bruker IFSv66) equipped with a $\mathrm{N}_{2}$-cooled MCT detector was employed. The measurements were carried out in attenuated total reflection (ATR) mode in Kretschmann geometry using an Si prism as IR active waveguide. A thin and nano-scale rough Au layer was coated onto the prism for conductivity/contacting purposes prior to MOF deposition/drop-casting. Deposition of the Au film is described elsewhere ${ }^{54}$. MOF drop-casting followed procedures as described above. The Au layer acted as a signal amplifier giving rise to strong surface-enhancement of IR signals of compounds close to the Au surface. In this way, we achieve to record SEIRA spectra of the MOF layers close to the electrode surface, which should exhibit excellent electronic contact. For applying potentials, the MOF-coated prism was mounted into a customized three-electrode containing spectro-electrochemical cell as described elsewhere ${ }^{54}$. A hydrogen-flamed cleaned Pt wire and $\mathrm{Ag} / \mathrm{AgCl}$ in $3 \mathrm{M} \mathrm{KCl}$ (DriRef, World Precision Instruments) acted as counter and reference electrode, respectively. 


\section{Data availability}

The datasets generated during and/or analyzed during the current study are available from the corresponding author on reasonable request.

Received: 18 September 2019; Accepted: 19 February 2020;

Published online: 16 March 2020

\section{References}

1. Voiry, D., Shin, H. S., Loh, K. P. \& Chhowalla, M. Low-dimensional catalysts for hydrogen evolution and $\mathrm{CO}_{2}$ reduction. Nat. Rev. Chem. 2, 0105 (2018).

2. Liu, M. et al. Enhanced electrocatalytic $\mathrm{CO}_{2}$ reduction via field-induced reagent concentration. Nature 537, 382-386 (2016).

3. Nielsen, D. U., Hu, X.-M., Daasbjerg, K. \& Skrydstrup, T. Chemically and electrochemically catalysed conversion of $\mathrm{CO}_{2}$ to $\mathrm{CO}$ with follow-up utilization to value-added chemicals. Nat. Catal. 1, 244-254 (2018).

4. Zheng, X. et al. Theory-guided $\mathrm{Sn} / \mathrm{Cu}$ alloying for efficient $\mathrm{CO}_{2}$ electroreduction at low overpotentials. Nat. Catal. 2, 55-61 (2018).

5. Sheng, W. et al. Electrochemical reduction of $\mathrm{CO}_{2}$ to synthesis gas with controlled $\mathrm{CO} / \mathrm{H}_{2}$ ratios. Energy Environ. Sci. 10, 1180-1185 (2017).

6. Liu, K.-H. et al. Composition-tunable synthesis of "clean" syngas via a onestep synthesis of metal-free pyridinic-N-enriched self-supported CNTs: the synergy of electrocatalyst pyrolysis temperature and potential. Green Chem. 19, 4284-4288 (2017).

7. Liu, X. et al. Understanding trends in electrochemical carbon dioxide reduction rates. Nat. Commun. 8, 15438 (2017)

8. Wang, Y. R. et al. Oriented electron transmission in polyoxometalatemetalloporphyrin organic framework for highly selective electroreduction of $\mathrm{CO}_{2}$. Nat. Commun. 9, 4466 (2018).

9. Gao, S. et al. Partially oxidized atomic cobalt layers for carbon dioxide electroreduction to liquid fuel. Nature 529, 68 (2016).

10. Jiao, J. et al. Copper atom-pair catalyst anchored on alloy nanowires for selective and efficient electrochemical reduction of $\mathrm{CO}_{2}$. Nat. Chem. 11, 222-228 (2019).

11. Nam, D.-H. et al. Metal-organic frameworks mediate $\mathrm{Cu}$ coordination for selective $\mathrm{CO}_{2}$ electroreduction. J. Am. Chem. Soc. 140, 11378-11386 (2018).

12. $\mathrm{Li}, \mathrm{X}$. et al. Exclusive Ni-N4 sites realize near-unity CO selectivity for electrochemical $\mathrm{CO}_{2}$ reduction. J. Am. Chem. Soc. 139, 14889-14892 (2017).

13. Kornienko, N. et al. Metal-organic frameworks for electrocatalytic reduction of carbon dioxide. J. Am. Chem. Soc. 137, 14129-14135 (2015).

14. Yang, F. et al. Highly efficient $\mathrm{CO}_{2}$ electroreduction on $\mathrm{ZnN}_{4}$-based singleatom catalyst. Angew. Chem. Int. Ed. 57, 12303-12307 (2018).

15. Zheng, T., Jiang, K. \& Wang, H. Recent advances in electrochemical $\mathrm{CO}_{2}$-toCO conversion on heterogeneous catalysts. Adv. Mater. 30, el802066 (2018).

16. Heidary, N., Harris, T., Ly, K. H. \& Kornienko, N. Artificial photosynthesis with metal and covalent organic frameworks (MOFs and COFs): challenges and prospects in fuel-forming electrocatalysis. Physiol. Plant. 166, 460-471 (2019).

17. Lin, $\mathrm{S}$. et al. Covalent organic frameworks comprising cobalt porphyrins for catalytic $\mathrm{CO}_{2}$ reduction in water. Science 349, 1208 (2015).

18. Hod, I. et al. Fe-porphyrin-based metal-organic framework films as highsurface concentration, heterogeneous catalysts for electrochemical reduction of $\mathrm{CO}_{2}$. ACS Catal. 5, 6302-6309 (2015).

19. Dong, R., Zhang, T. \& Feng, X. Interface-assisted synthesis of 2D Materials: trend and challenges. Chem. Rev. 118, 6189-6235 (2018).

20. Zhao, M. et al. Two-dimensional metal-organic framework nanosheets: synthesis and applications. Chem. Soc. Rev. 47, 6267-6295 (2018).

21. Zhang, H., Nai, J., Yu, L. \& Lou, X. W. Metal-organic-framework-based materials as platforms for renewable energy and environmental applications. Joule 1, 77-107 (2017)

22. Duan, J., Chen, S. \& Zhao, C. Ultrathin metal-organic framework array for efficient electrocatalytic water splitting. Nat. Commun. 8, 15341 (2017)

23. Feng, D. et al. Robust and conductive two-dimensional metal-organic frameworks with exceptionally high volumetric and areal capacitance. Nat. Energy 3, 30-36 (2018)

24. Huang, X. et al. Superconductivity in a copper(II)-based coordination polymer with perfect kagome structure. Angew. Chem. Int. Ed. 130, 152-156 (2018)

25. Dong, R. et al. Large-area, free-standing, two-dimensional supramolecular polymer single-layer sheets for highly efficient electrocatalytic hydrogen evolution. Angew. Chem. Int. Ed. 54, 12058-12063 (2015).

26. Clough, A. J., Yoo, J. W., Mecklenburg, M. H. \& Marinescu, S. C. Twodimensional metal-organic surfaces for efficient hydrogen evolution from water. J. Am. Chem. Soc. 137, 118-121 (2015).

27. Miner, E. M. et al. Electrochemical oxygen reduction catalysed by $\mathrm{Ni}_{3}$ (hexaiminotriphenylene) 2 . Nat. Commun. 7, 10942 (2016).

28. Zhong, H. et al. A phthalocyanine-based Layered two-dimensional conjugated metal-organic framework as a highly efficient electrocatalyst for the oxygen reduction reaction. Angew. Chem. Int. Ed. 131, 10787-10792 (2019).
29. Diercks, C. S., Liu, Y., Cordova, K. E. \& Yaghi, O. M. The role of reticular chemistry in the design of $\mathrm{CO}_{2}$ reduction catalysts. Nat. Mater. 17, 301-307 (2018).

30. Hansen, H. A., Varley, J. B., Peterson, A. A. \& Nørskov, J. K. Understanding trends in the electrocatalytic activity of metals and enzymes for $\mathrm{CO}_{2}$ reduction to CO. J. Phys. Chem. Lett. 4, 388-392 (2013).

31. Ju, W. et al. Understanding activity and selectivity of metal-nitrogen-doped carbon catalysts for electrochemical reduction of $\mathrm{CO}_{2}$. Nat. Commun. 8, 944 (2017).

32. Bagger, A., Ju, W., Varela, A. S., Strasser, P. \& Rossmeisl, J. Single site porphyrine-like structures advantages over metals for selective electrochemical $\mathrm{CO}_{2}$ reduction. Catal. Today 288, 74-78 (2017)

33. Zhang, J. et al. Copper dopants improved the hydrogen evolution activity of earth-abundant cobalt pyrite catalysts by activating the electrocatalytically inert sulfur sites. J. Mater. Chem. A 5, 17601-17608 (2017).

34. Nagatomi, H., Yanai, N., Yamada, e, Shiraishi, K. \& Kimizuka, N. Synthesis and electric properties of a two-dimensional metal-organic framework based on phthalocyanine. Chem. Eur. J. 24, 1803-1810 (2018).

35. Sheberla, D. et al. High electrical conductivity in $\mathrm{Ni}_{3}(2,3,6,7,10,11$ hexaiminotriphenylene) ${ }_{2}$, a semiconducting metal-organic graphene analogue. J. Am. Chem. Soc. 136, 8859-8862 (2014).

36. Campbell, M. G., Sheberla, D., Liu, S. F., Swager, T. M. \& Dinca, M. $\mathrm{Cu}_{3}$ (hexaiminotriphenylene) $)_{2}$ : an electrically conductive 2D metal-organic framework for chemiresistive sensing. Angew. Chem. Int. Ed. 54, 4349-4352 (2015).

37. Hoang, T. T. H. et al. Nano porous copper-silver alloys by additive-controlled electro-deposition for the selective electroreduction of $\mathrm{CO}_{2}$ to ethylene and ethanol. J. Am. Chem. Soc. 140, 5791-5797 (2018).

38. Rochet, F. et al. Copper phthalocyanine on $\mathrm{Si}(111)-7 \times 7$ and $\mathrm{Si}(001)-2 \times 1$ : an XPS/AES and STM study. Surf. Sci. 319, 10-20 (1994).

39. Islam, M. N., Ghosh, T. B., Chopra, K. L. \& Acharya, H. N. XPS and X-ray diffraction studies of aluminum-doped zinc oxide transparent conducting films. Thin Solid Films 280, 20-25 (1996).

40. Weng, Z. et al. Active sites of copper-complex catalytic materials for electrochemical carbon dioxide reduction. Nat. Commun. 9, 415 (2018).

41. Chaboy, J., Muñoz-Páez, A., Carrera, F., Merkling, P. \& Marcos, E. S. Ab initiox-ray absorption study of copper K-edge XANES spectra in $\mathrm{Cu}$ (II) compounds. Phys. Rev. B 71, 134208 (2005)

42. Wang, L. et al. Quantitative Zn speciation in zinc-containing steelmaking wastes by X-ray absorption spectroscopy. J. Anal. Spectrom. 27, 1667 (2012).

43. Yadav, A. K. et al. Local structure studies of Ni doped ZnO/PVDF composite free-standing flexible thin films using XPS and EXAFS studies. J. Polym. Res. 23, 265 (2016).

44. Kittilstved, K. R. et al. Direct kinetic correlation of carriers and ferromagnetism in $\mathrm{Co}^{2+}$ : ZnO. Phys. Rev. Lett. 97, 037203 (2006).

45. Varela, A. S. et al. Metal-doped nitrogenated carbon as an efficient catalyst for direct $\mathrm{CO}_{2}$ electroreduction to $\mathrm{CO}$ and hydrocarbons. Angew. Chem. Int. Ed. 54, 10758-10762 (2015)

46. $\mathrm{Wu}, \mathrm{Y}$. et al. Electroreduction of $\mathrm{CO}_{2}$ Catalyzed by a heterogenized $\mathrm{Zn}$ porphyrin complex with a redox-innocent metal center. ACS Cent. Sci. 3, 847-852 (2017).

47. Heyes, J., Dunwell, M. \& Xu, B. $\mathrm{CO}_{2}$ reduction on $\mathrm{Cu}$ at low overpotentials with surface-enhanced in situ spectroscopy. J. Phys. Chem. C 120, 17334-17341 (2016)

48. Heidary, N., Ly, K. H. \& Kornienko, N. Probing $\mathrm{CO}_{2}$ conversion chemistry on nanostructured surfaces with Operando vibrational spectroscopy. Nano Lett. 19, 4817-4826 (2019)

49. Wang, X., Andrews, L., Manceron, L. \& Marsden, C. Infrared spectra and DFT calculations for the coinage metal hydrides $\mathrm{MH},\left(\mathrm{H}_{2}\right) \mathrm{MH}, \mathrm{MH}_{2}, \mathrm{M}_{2} \mathrm{H}, \mathrm{M}_{2} \mathrm{H}^{-}$, and $\left(\mathrm{H}_{2}\right) \mathrm{CuHCu}$ in solid argon, neon, and hydrogen. J. Phys. Chem. A 107, 8492-8505 (2003)

50. Perdew, J. P., Burke, K. \& Ernzerhof, M. Generalized gradient approximation made simple. Phys. Rev. Lett. 77, 3865-3868 (1996).

51. Kresse, G. \& Hafner, J. Ab initio molecular dynamics for liquid metals. Phys. Rev. B 47, 558-561 (1993).

52. Kresse, G. \& Furthmüller, J. Efficiency of ab-initio total energy calculations for metals and semiconductors using a plane-wave basis set. Comput. Mater. Sci. 6, 15-50 (1996).

53. Grimme, S. Semiempirical GGA-type density functional constructed with a long-range dispersion correction. J. Comput. Chem. 27, 1787-1799 (2006).

54. Ly, H. K. et al. 2nd coordination sphere controlled electron transfer of iron hangman complexes on electrodes probed by surface enhanced vibrational spectroscopy. Chem. Sci. 6, 6999-7007 (2015).

\section{Acknowledgements}

This work is financially supported by EU Graphene Flagship (GrapheneCore2 785219) and Coordination Networks: Building Blocks for Functional Systems (SPP 1928, COORNET), as well as the German Science Council and Center of Advancing 
Electronics Dresden (cfaed). This project also has received funding from the European Research Council (ERC) under the European Union's Horizon 2020 research and innovation program (FC2DMOF, grant agreement No. 852909). H.Z. gratefully acknowledges funding from the Alexander von Humboldt Foundation. I.M.W. acknowledges the Cluster of Excellence UniSysCat. We acknowledge Dresden Center for Nanoanalysis (DCN) at TUD and Dr. Petr Formanek (Leibniz Institute for Polymer Research, IPF, Dresden) for the use of facilities. We also thank Mr. Zhiyong Wang and Dr. Chongqing Yang for helpful discussions. We thank the beamline scientists at BL14W1 and BL15U1 of the Shanghai Synchrotron Radiation Facility for the XAFS measurements. We thank Mr. Chenbao Lu and Prof. Xiaodong Zhuang for the in-situ XAS electrochemical cell setup, as well as Wei Li for the ex-situ Raman testing. We thank $\mathrm{Mr}$. Zhe Zhang for helping prepare the Au/CP current collector. The computational support from the HZDR computing cluster is gratefully appreciated.

\section{Author contributions}

R.D. and X.F. conceived and designed the project. H.Z. synthesized the precursor and MOFs and conducted the morphology, structural, compositional and electrochemical $\mathrm{CO}_{2} \mathrm{RR}$ performance. M.G.-A. and A.V.K. contributed to the theoretical calculations. K.H.L. and I.M.W. contributed to the in-situ FT-IR measurements and analysis. J.G. and D.M. help with the $\mathrm{CO}_{2} \mathrm{RR}$ performance testing. Jichao Z. conducted Operando and ex-situ XAS and EXAFS measurements and related analysis. M.W. contributed to the ligand's synthesis. Z.L. and E.Z. contributed to the TEM testing. Jian Z., E.B. and S.K. contributed to the discussion of the MOFs synthesis and electrochemical performance. H.Z., R.D., K.H.L. and X.F. co-wrote the paper. All the authors discussed the results and commented on the manuscript.

\section{Competing interests}

The authors declare no competing interests.

\section{Additional information}

Supplementary information is available for this paper at https://doi.org/10.1038/s41467020-15141-y.

Correspondence and requests for materials should be addressed to R.D. or X.F.

Peer review information Nature Communications thanks the anonymous reviewer(s) for their contribution to the peer review of this work. Peer reviewer reports are available.

Reprints and permission information is available at http://www.nature.com/reprints

Publisher's note Springer Nature remains neutral with regard to jurisdictional claims in published maps and institutional affiliations.

(c) (i) Open Access This article is licensed under a Creative Commons Attribution 4.0 International License, which permits use, sharing, adaptation, distribution and reproduction in any medium or format, as long as you give appropriate credit to the original author(s) and the source, provide a link to the Creative Commons license, and indicate if changes were made. The images or other third party material in this article are included in the article's Creative Commons license, unless indicated otherwise in a credit line to the material. If material is not included in the article's Creative Commons license and your intended use is not permitted by statutory regulation or exceeds the permitted use, you will need to obtain permission directly from the copyright holder. To view a copy of this license, visit http://creativecommons.org/ licenses/by/4.0/.

(c) The Author(s) 2020 